\title{
Pereirina e Plasmodios
}

(Nota prévia)

\author{
Dr. Aristides G. Guimarães, Assis- \\ tente de Parasitologia. \\ Mendonça Cortez, Auxiliar volun- \\ tario de Parasitologia.
}

A acção dos medicamentos sobre os Plasmodios poderia ser estu. dada "in vitro", ou por exames no sangue dos doentes submettidos ao tratamento.

Para o quinino, Lo Monacho e Panichi, em seguida a experiencias feitas em gattas pendentes, admittiram que tal medicamento agia destruindo a hematia e libertando o schizonte.

Mas, "in vitro", as causas de erro evidentemente são numerosas. Por isso, preferimos seguir "pari-passu" pelo exame do sangue peripherico, as mutações solffridas pelos parasitas, quando submettído o doente ao tratamento. Tal o methodo seguido por Mannaberg, Romanowsky, Baccelli, Golgi, Marchiafava, Bignami, Zismann, Schaudinn, para o estudo da acção do tratamento quinico. Orientando_nos nos trabalhos desses auctores, procuravamos comparar á acção do quinino os resultados obtidos com a pereirina.

Quanto á acção do quinino na terçan benigna, é sabido que elle age energicamente sobre os hematozoarios, ainda quando dado s6mente 2 1/2 horas antes do acesso. Os schizontes novos e velhos e os gametas ainda não maduros são alterados. O plasma apresenta sulcos profundos, mostrando-se em parte destruido. O nucleo fragmenta-se, e a chromatina mostra-se dispersa. E' pricipalmente sobre os merozoites recentes que o medicamento tem maior acção: coram-se mal, os seus contornos mostram-se diffusos, o nucleo a. penas apparente e completámente fragmentado. Quer isso dizer que, se o quinino administrado tão proximo ao acesso não tem o poder de o supprimir, pelo menos faz desapparecer uma geração de parasitas. Ao contrario, a sua acção sobre os gametas maduros parece insignificante.

Tendo em vista os casos em que empregamos a pereirina, quernos parecer que ella tem acção manifesta sobre o "Plasmodium vivax", principalmente sobre os schizontes, porque depois do tratamento, os parasitas se encontram sempre em menor numero e com alterações semelhantes ás obtidas com o quinino.

Em varios casos verificamos desapparecimento completo de hematozoarios, constatado em exames de sangue logo em seguida ao tratamento e tambem mezes após; em outros, grande diminuição. Para não alongarmos demasiado esta simples nota previa, citare- 
mos apenas 2 casos em que o resultado obtido foi, por assim dizer, medio.

Em caso, datando de dois mezes, febre diaria, contamos antes do tratamento, em uma linha de $2.5 \mathrm{~mm}$. (preparação corada de sangue peripherico):

Anneis novos P. vivax.

Formas amiboides P. vivax.

" em divisão P. vivax

Rosaceas P. vivax :

Depois do tratamento, em uma linha de $20 \mathrm{~mm} .$, contamos:

Anneis novos $P$ vivax

Flormas amiboides P. vivax

Em outro caso, uma infecção mixta pelo P. vivax e pelo $\mathrm{P}$ falciparum, caso com toda a symptomalogia classica, datando já de 3 mezes, dizendo ter anteriorente feito tratamento, á sua entrada no hospital contamos em uma linha de $30 \mathrm{~mm}$.:

Anneis novos P. vivax.

Formas amiboides $\mathrm{P}$ vivax. .

" em divisão $\mathrm{P}$ vivax

Crescentes $P$ falciparum

Depois do tratamento, em uma linha de $21 \mathrm{~mm}$., contamos:

Anneis novos P. vivax

Formas amiboides P. vivax.

Crescentes P. falciparum

Além d'essas variações de numero, devem ser levadas em conta as modificações ou alterações que apresentam os parasitas, analo. gas ás que citamos para o quinino.

Quanto ao "Plasmodium falciparum", a acção do quinino é sobre -elle menos rapida que sobre o "Plasmodium vivax", parecendo que elle age apenas sobre as formas em divisão, sendo necessario repetir a sua administração para attingir successivamente todas as gerações de parasitas que vivem ao mesmo tempo no sangue do doente. O medicamento parece inoffensivo para com os gametas.

Pelos casos de terçan maligna em que até agora administramos pereirina, quer parecer-nos que ella age sobre os schizontes do "Plasmodium falciparum", mas menos intensamente que sobre os de "Plasmodium vivax"

Martirano e Giraldi affirmam que uma dose de quinino faz apparecer no sangue peripherico um maior numero de crescentes Polletini affirma que o mesmo se dá, quando o tratamento pelo qui. nino em alta dose é prolongado 'alem do momento em que a febre desapparece. Mas sob o effeito de um tratamento prolongado, elles 
desapparecem tambem geralmente (Councilman, Golgi, Arnaud, Laveran).

Com respeito á pereirina, n'esse sentido, nada podemos affirmar, a não ser que, nos casos observados, o numero de crescentes se manteve mais ou menos constante.

Oppurtunamente diremos o que de um maior numero de casos, em cuja observação nos enpenhamos, se poder concluir.

Nota preliminar sobre seis casos de blastomycose ultimamente observados no hospital da Santa Casa de Misericordia de S. Paulo

Dr. Pedro Dias da Silva e Doutorando Ernesto de Souza Campos.

A's tres observações de blastomycose, publicadas nos numeros 5 e 6 desta Revista, juntamos mais seis casos observados no Hospital da Santa Casa de Misericordia, desta cidade, desde Agosto do anno passado até esta data, todos oriundos. do interior do Estado, con excepção de um, proveniente de Montevidéu.

Esses seis casos, por nós observados no curto periodo de um anno, em úm unico hospital, vêm por si provar a relativa frequencia da blastomycose em nosso meio e nos faz acreditar que é, certamente, elevado o numero de doentes atacados desta molestia, que têm passado despercebidos e considerados como portadores do outras entidades morbidas.

Todos esses casos, cujas observações publicamos, tinhąm o caracter de generalisação com lesões visceraes intensas e grande compromettimento do systema lymphatico, evidenciado pelas tumefacções das pleiades ganglionares de diversas regiões, onde proliferavam abundantissimos blastomycetos.

Em a nossa observação numero IV. notámos uma feição clinica toda especial, com o curioso phenomeno que, aliás, já foi uma vez observado por Corselli e Frisco em um caso de blastomycose, por esses autores publicado no Cbl. f. Backt. 1895 XVIII, qual o de uma ascite chylosa. No liquido chyloso encontrámos os blastomycetos, assim como, mais tarde (na necroscopia) na folha parietal do peritoneo. Esse mesmo doente era portador de uma pleurisia con dərrane, en cujo liquido tambem encontrámos parasitas. 